\title{
Critical evaluation of the factorial and heart-rate recording methods for the determination of energy expenditure of free-living elderly people
}

\author{
BY BEATRICE MORIO ${ }^{1}$, PATRICK RITZ ${ }^{1}$, ELISABETH VERDIER ${ }^{1}$ \\ CHRISTOPHE MONTAURIER ${ }^{1}$, BERNARD BEAUFRERE ${ }^{1}$ AND \\ MICHEL VERMOREL ${ }^{2 *}$ \\ ${ }^{1}$ CRNH, Université d'Auvergne, Laboratoire de Nutrition Humaine, BP 321-58 rue Montalembert, \\ 63009 Clermont-Ferrand cédex 1, France \\ ${ }^{2}$ INRA, U. Métabolismes énérgétique et lipidique, 63122 Saint-Genès-Champanelle, France
}

(Received 17 December 1996 - Revised 19 March 1997 - Accepted 9 May 1997)

\begin{abstract}
The aim of the present study was to validate against the doubly-labelled water (DLW) technique the factorial method and the heart rate (HR) recording method for determining daily energy expenditure (DEE) of elderly people in free-living conditions. The two methods were first calibrated and validated in twelve healthy subjects (six males and six females; 70.1 (SD 2.7) years) from opencircuit whole-body indirect calorimetry measurements during three consecutive days and during $1 \mathrm{~d}$ respectively. Mean energy costs of the various usual activities were determined for each subject using the factorial method, and individual relationships were set up between HR and energy expenditure for the HR recording method. In free-living conditions, DEE was determined over the same period of time by the DLW, the factorial and the HR recording methods during 17,14 and $4 \mathrm{~d}$ respectively. Mean free-living DEE values for men estimated using the DLW, the factorial and the HR recording methods were 12.8 (SD 3.1), 12.7 (SD 2.2) and 13.5 (SD 2.7) MJ/d respectively. Mean free-living DEE values for women were 9.6 (SD 0.8), 8.8 (SD 1.2) and 10.2 (SD 1.5) MJ/d respectively. No significant differences were found between the three methods for either sex, using the Bland \& Altman (1986) test. Mean differences in DEE of men were - 0.9 (SD 11.8) \% between the factorial and DLW methods, and +4.7 (SD 16.1) \% between the HR recording and DLW methods. Similarly, in women, mean differences were -7.7 (SD 12.7) \% between the factorial and DLW methods, and +5.9 (SD 8.8) \% between the HR recording and DLW methods. It was concluded that the factorial and the HR recording methods are satisfactory alternatives to the DLW method when considering the mean DEE of a group of subjects. Furthermore, mean energy costs of activities calculated in the present study using the factorial method were shown to be suitable for determining free-living DEE of elderly people when the reference value (i.e. sleeping metabolic rate) is accurately measured.
\end{abstract}

Energy expenditure: Free-living conditions: Elderly

Daily energy needs tend to be reduced with ageing partly because of a decrease in active cell mass (Forbes \& Reina, 1976) and in duration and intensity of physical activities (Prentice, 1992). Furthermore, the large variations in daily energy needs of elderly people shown in a recent meta-analysis (Black et al. 1996) underline the heterogeneity of the population. It is important that adequate energy allowances are defined for each group of elderly people to avoid energy imbalance which could result in weight loss and a further decline in lean body mass. The latter is strategically important for physical and mental autonomy. 
Energy requirements can be assessed by using methods based on determination of either metabolizable energy (ME) intake or energy expenditure (EE). Dietary records of 3 or $4 \mathrm{~d}$ were shown to underestimate notably the energy needs of elderly people, especially for women (Pannemans \& Westerterp, 1993; Visser et al. 1995a). Therefore, measurements of daily energy expenditure (DEE) are required.

Whole-body indirect calorimetry provides accurate and precise measurements of energy expenditure throughout the day. However, this method tends to underestimate freeliving DEE because of a lower spontaneous activity of the subjects living in calorimeters (Seale, 1995). Adapted methods are needed for accurate determination of DEE in freeliving conditions.

The validity of the doubly-labelled water (DLW) method for free-living DEE determination was demonstrated by Schoeller (1988), but its use is limited by the high cost of the isotopes and analysis and by the necessary expertise in calculations of $\mathrm{CO}_{2}$ production. Two alternative methods have been shown to be suitable for estimating freeliving DEE of groups of children (Livingstone et al. 1992; Bitar et al. 1996) or adults (Geissler et al. 1986; Spurr et al. 1988; Ceesay et al. 1989; Livingstone et al. 1990): the factorial method and the heart rate (HR) recording method.

The factorial method is based on the calculation of DEE from a record of the activities (type and duration) in free-living conditions and the energy cost of each activity, determined by indirect calorimetry. The method has not been validated in free-living conditions for elderly people, although several studies carried out in elderly subjects did determine the energy costs of various activities (Calloway \& Zanni, 1980; Voorrips et al. 1993; Visser et al. 1995c) or of percentage of time spent on activities (Patrick et al. 1986; Dalosso et al. 1988).

The HR recording method is based on free-living HR recordings and individual relationships between HR and EE established from indirect calorimetry measurements. Again, the method has not been validated in free-living elderly subjects.

The aim of the present study was, therefore, to validate in free-living conditions the factorial method and the HR recording method against the DLW method in elderly people for the determination of DEE. The two methods first had to be calibrated and validated from whole-body indirect calorimetry measurements. In addition, ME intake was determined from dietary records in free-living conditions.

\section{SUBJECTS AND METHODS}

\section{Subjects}

Twelve subjects (six men, six women) with various typical physical activity levels (from sedentary to very active), aged 70.1 (SD 2.7) years participated in this study. All subjects had taken a medical examination. They were healthy and were not receiving any medication known to influence energy metabolism. Each subject received a complete explanation of the purpose and procedures of the investigation and signed an informed consent form. The study protocol was approved by the regional Medical School Ethical Committee.

\section{Body composition measurements}

Body weight was measured to the nearest $0.01 \mathrm{~kg}$ on a Mettler ID1 Multirange scale (Mettler Instrumente AG, GreifenSMR, Switzerland). Height was measured to the nearest $2 \mathrm{~mm}$. Total body water was calculated from the ${ }^{18} \mathrm{O}$ dilution space corrected for the $1 \%$ 
overestimation (Schoeller et al. 1980). Lean body mass was calculated assuming a 732 $\mathrm{g} / \mathrm{kg}$ water content (Sheng \& Huggins, 1979).

\section{Study design}

An overview of the protocol is given in Fig. 1. During a $7 \mathrm{~d}$ run-in period, daily activities (nature and duration) and food consumption were recorded at home by the volunteers in order to set up a program of activities and menus as close as possible to their normal life habits for the stay in whole-body calorimeters. Then, the subjects spent $36 \mathrm{~h}$ (one night and one complete day) in the calorimeters to get used to the equipment. Thereafter, during the study-period, the volunteers spent $84 \mathrm{~h}$ (i.e. one night and three whole days) in the calorimeters where EE and HR were measured continuously to establish basal data for the factorial and the HR recording methods. In free-living conditions, DEE was determined using the DLW method, the factorial method and the HR recording method during 17,14 and $4 \mathrm{~d}$ respectively, while food consumption was recorded for $7 \mathrm{~d}$.

\section{Doubly-labelled water method}

During the $7 \mathrm{~d}$ run-in period urine was collected from the second void every morning to determine the variations in deuterium and ${ }^{18} \mathrm{O}$ natural abundance. Thereafter, on coming out of the calorimeters after the adaptation period, while fasting and resting, volunteers received orally an accurately weighed dose of about $0.15 \mathrm{~g} \mathrm{H}_{2}^{18} \mathrm{O} / \mathrm{kg}$ body weight $(10.3 \%$ water enrichment, Eurisotop, CEA Group, Gif-sur-Yvette, France) and $0.12 \mathrm{~g}^{2} \mathrm{H}_{2} \mathrm{O} / \mathrm{kg}$ body weight (99.9\% water enrichment, Sigma Chemical Co., St Louis, MO, USA). Urine samples were collected before the dose and then every morning for $17 \mathrm{~d}$. Date and time of the collection were recorded for each sample.

${ }^{18} \mathrm{O}:{ }^{16} \mathrm{O}$ isotopic ratios were measured in duplicate by gas chromatography-mass spectrometry (VG Isochrom-ægas, VG Isotech, Ches.) using the $\mathrm{CO}_{2}-\mathrm{H}_{2} \mathrm{O}$ equilibration method as described by Wong et al. (1987). ${ }^{2} \mathrm{H}:{ }^{1} \mathrm{H}$ isotopic ratios were measured in duplicate by (dual-inlet) mass spectrometry using the technique with Indiana $\mathrm{Zn}$ (Biogeochemical Laboratories, Indiana University, Bloomington, IN, USA) as described by Wong et al. (1987). All isotopic enrichments were expressed as $\delta \%$ relative to the

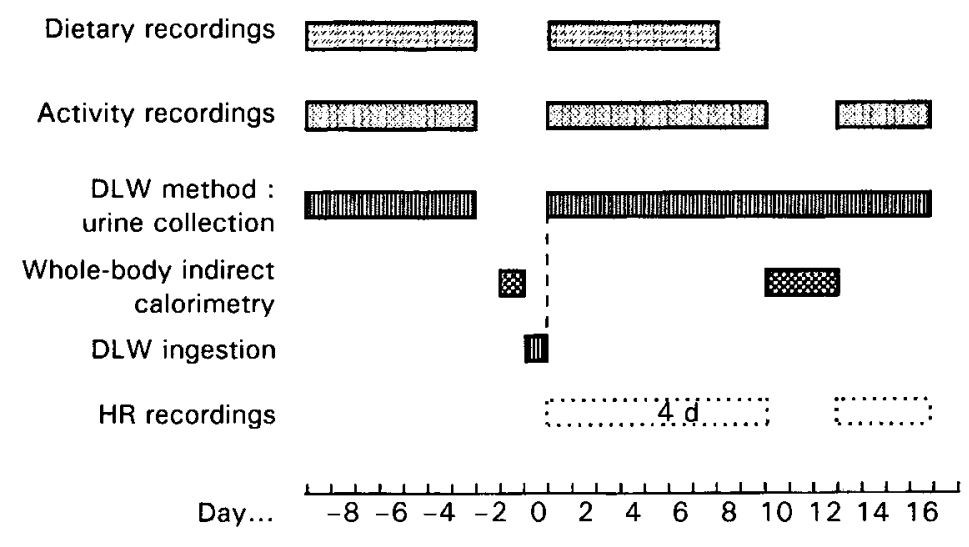

Fig. 1. Study design. DLW, doubly-labelled water; HR, heart rate. 
international standard Vienna Standard Mean Ocean Water (V-SMOW) (Gonfiantini, 1978).

The isotope dilution spaces were derived from the intercept of the isotope disappearance curves (Cole \& Coward, 1992). $\mathrm{CO}_{2}$ production was calculated with the multipoint method (Cole \& Coward, 1992). $\mathrm{CO}_{2}$ production was converted into energy expenditure ( $\mathrm{DEE}_{\mathrm{DLW}}$ ) using the mean $\mathrm{RQ}$ measured during the $3 \mathrm{~d}$ stay in the calorimeters and the energy equivalent per litre $\mathrm{CO}_{2}$ as described by Elia (1991). Imprecision in $\mathrm{CO}_{2}$ production as calculated with the multipoint method, and arising from natural abundance variation, was determined as described by Ritz et al. (1996).

\section{Activity programs in the calorimeters}

From the record of activities performed during the run-in period, appropriate daily activity programs were worked out for each volunteer for the $3 \mathrm{~d}$ stay in the calorimeter to reproduce their usual physical activity level. Particular attention was given to reproducing the usual intensity for each activity, the latter being adapted to the equipment available in the chambers. Walking, jogging and cycling were reproduced using a treadmill and a cycleergometer. Housekeeping activities were dusting, cleaning windows and simulation of ironing. Housekeeping activities were also simulated by weight lifting with a $2 \mathrm{~kg}$ load. Other activities were simulation of handy-work, wall painting, gardening using a $5 \mathrm{~kg}$ ballasted spade or pulling a $4 \mathrm{~kg}$ load, and gymnastics and yoga according to the subject's habits. During the rest of the time, activities were free and recorded by the volunteers.

\section{Indirect calorimetry measurements}

EE and HR were measured continuously in two large open-circuit calorimetric chambers during the adaptation and study periods. Gas exchanges were computed from outlet air flow, differences in gas concentrations, atmospheric pressure, chamber air temperature and hygrometry and corrected for the drifts and time response of the gas analysers and the variations of the volume of $\mathrm{CO}_{2}$ and $\mathrm{O}_{2}$ in the chambers (Vermorel et al. 1995). The validity of gas exchange measurements was checked gravimetrically (Vermorel et al. 1995). The recovery was $100.6 \%$ for $\mathrm{O}_{2}$ and $103.4 \%$ for $\mathrm{CO}_{2}$ over 15 and 30 min periods, and was 99.9 (SD 1.3) \% for $\mathrm{O}_{2}$ and 98.8 (SD 1.2) \% for $\mathrm{CO}_{2}$ during a 6-8h period. EE was calculated using the equation of Weir (1949) from the minute-to-minute measurement of gas exchanges corrected for the urinary $\mathrm{N}$ excretion.

Mean sleeping metabolic rate (SMR) was taken as the energy expended each night of the study period from the second hour after which the subjects went to bed to 5-6h later, and extrapolated to $24 \mathrm{~h}$. The energy expenditure corresponding to the various activities simulated during the study period was computed over 15 or $30 \mathrm{~min}$ for high or low-tomoderate intensity activities, respectively. The mean energy cost of each activity was expressed as a multiple of SMR.

\section{Factorial method: calibration, validation and practical applications}

For the validation of the factorial method against whole-body indirect calorimetry, $\mathrm{DEE}_{\mathrm{FACT}}$ was calculated using the activities recorded during the adaptation period to the calorimeters and the energy cost of each activity measured during the study period in the calorimeters for each volunteer. The calculated $\mathrm{DEE}_{\mathrm{FACT}}$ was compared with the $\mathrm{DEE}_{\mathrm{CAL}}$ measured by indirect calorimetry. 
In free-living conditions the volunteers were asked to record their activities as accurately as possible ( $\pm 5 \mathrm{~min}$ ) for $14 \mathrm{~d}$. The various daily activities were distributed among eighteen types ranging from sleeping to running. The corresponding DEE $\left(\mathrm{DEE}_{\mathrm{FACT}}\right)$ was calculated from the duration, the unitary energy cost of the different activities and SMR determined for each volunteer in the calorimeters.

\section{Heart rate recording method: calibration, validation and practical applications}

From the $3 \mathrm{~d}$ measurements in the calorimeters where HR was recorded minute-by-minute using telemetry (Life Scope 6, Nihon Kohden Corporation, Tokyo, Japan), individual relationships were set up between HR and EE averaged over $30 \mathrm{~min}$ periods. For each volunteer, the best fitted relationship was chosen between linear, exponential or polynomial models from residual standard deviation and residuals, especially for the lowest and highest HR (Bitar et al. 1996). For the validation of the HR recording method against whole-body indirect calorimetry, $\mathrm{DEE}_{\mathrm{HR}}$ was calculated using the $\mathrm{HR}$ kinetics recorded during the adaptation period to the calorimeters and each individual HR-EE relationship established during the study period. The calculated $\mathrm{DEE}_{\mathrm{HR}}$ was compared with the $\mathrm{DEE}_{\mathrm{CAL}}$ measured by indirect calorimetry.

In free-living conditions, HR was recorded minute-by-minute using Sport Testers (PE4000, Kempele, Finland) for $4 \mathrm{~d}$ randomly chosen during the study period. DEE $\left(\mathrm{DEE}_{\mathrm{HR}}\right)$ was then calculated using each individual relationship.

\section{Assessment of dietary intake}

Before completing the two $7 \mathrm{~d}$ weighed dietary records, instructions were given individually by the dietitian. Furthermore, quality and logic of food recordings were checked twice during each recording period by an investigator who visited the subjects at home. ME and macronutrient intakes were determined from the two dietary records (Fig. 1) and using the software GENI with French (REGAL) and German (SOUCI) tables for food composition (Micro-6, Villers-les-Nancy, France). Menus for the $3 \mathrm{~d}$ stay in the calorimeters were worked out by the dietitian for each volunteer from the first dietary intake record.

\section{Statistical analysis}

Results are reported as mean values and standard deviations. The Student's (paired or unpaired where applicable) two-tail $t$ test was used for comparison of means. Methods were compared two-by-two using the Bland-Altman method (Bland \& Altman, 1986). Results were considered to be statistically significant at the $5 \%$ level.

\section{RESULTS}

\section{Subject characteristics}

Subject characteristics are given in Table 1 . Body weight of men ranged from 58.2 to $91.5 \mathrm{~kg}$, lean body mass from 44.4 to $61.8 \mathrm{~kg}$ and body fatness from 20.8 to $37.0 \%$. Body weight of women ranged from 53.7 to $77.6 \mathrm{~kg}$, lean body mass from 32.6 to $51.5 \mathrm{~kg}$ and fat mass content from 33.6 to $40.5 \%$. No significant differences were found between men and 
Table 1. Characteristics of the subjects

(Mean values and standard deviations)

\begin{tabular}{|c|c|c|c|c|}
\hline & \multicolumn{2}{|c|}{$\operatorname{Men}(n 6)$} & \multicolumn{2}{|c|}{ Women (n 6) } \\
\hline & Mean & SD & Mean & SD \\
\hline Age (years) & $68 \cdot 8$ & 2.5 & $71 \cdot 3$ & $2 \cdot 4$ \\
\hline Weight $(\mathrm{kg})$ & 74.9 & 12.4 & 67.7 & 7.7 \\
\hline Height (m) & 1.666 & 0.073 & 1.589 & 0.066 \\
\hline BMI $\left(\mathrm{kg} / \mathrm{m}^{2}\right)$ & $26 \cdot 9$ & 3.8 & 26.8 & 1.5 \\
\hline LBM (kg) & 52.9 & $5 \cdot 9$ & $42 \cdot 2 * *$ & $6 \cdot 2$ \\
\hline Fat mass (\%) & $28 \cdot 6$ & 6.5 & $38 \cdot 2 *$ & $2 \cdot 5$ \\
\hline
\end{tabular}

LBM, lean body mass.

Mean values were significantly different from those for men: ${ }^{*} P<0.05, * * P<0.01$.

women for body weight. However, women had $10.7 \mathrm{~kg}$ less lean body mass $(P<0.01)$ and $9.6 \%$ more fat mass content $(P<0.05)$ than men.

\section{Doubly-labelled water method}

Mean ${ }^{2} \mathrm{H}:{ }^{18} \mathrm{O}$ dilution spaces ratio was 1.027 (SD 0.029). Mean ${ }^{2} \mathrm{H}$ disappearance rate was 9.2 (SD 2.1) \% per d (6.8-13.7\% per d). Mean ${ }^{18} \mathrm{O}$ disappearance rate was 11.8 (SD 2.2) \% per d (9.1-16.8\% per d). Water turnover was 3.2 (SD 0.6) litres/d (2.5-4.4 litres/d). Mean RQ measured during the study period in the calorimeters was 0.859 (SD 0.026) $(0.815-$ 0.910 ), its within-subject CV averaged 1.44 (SD 0.54) \% (0.66-2.49\%) over $3 \mathrm{~d}$. Mean $\mathrm{DEE}_{\mathrm{DLw}}$ was $33.3 \%$ higher in men than in women $(P<0.01$; Table 2$)$. It ranged from 9.9 to $18.7 \mathrm{MJ} / \mathrm{d}$ in men and from 8.3 to $10.4 \mathrm{MJ} / \mathrm{d}$ in women. Within-subject standard error of estimate of $\mathrm{CO}_{2}$ production averaged 3.9 (SD 2.1) \% (2.1-9.6\%). It resulted from the errors calculated with the multipoint method (1.9 (SD 0.9)\%) and arising from natural abundance variation $(3 \cdot 2$ (SD 2.1)\%).

Table 2. Daily energy expenditure (DEE; MJ) of elderly subjects measured in calorimeters for $3 d\left(D E E_{C A L}\right)$ and measured under free-living conditions using the doubly-labelled water method $\left(D E E_{D L W}\right)$, the factorial method $\left(D E E_{F A C T}\right)$ and the heart rate recording method $\left(D E E_{H R}\right)$ for 17,14 and $4 d$ respectively, together with metabolizable energy intake (MEI) assessed under free-living conditions from $7 d$ weighed food records

(Mean values and standard deviations for six subjects)

\begin{tabular}{|c|c|c|c|c|c|c|c|c|c|c|}
\hline & \multirow{2}{*}{\multicolumn{2}{|c|}{$\frac{\text { Calorimeters }}{\mathrm{DEE}_{\mathrm{CAL}}}$}} & \multicolumn{8}{|c|}{ Free-living conditions } \\
\hline & & & \multicolumn{2}{|c|}{$\mathrm{DEE}_{\mathrm{DLW}}$} & \multicolumn{2}{|c|}{$\mathrm{DEE}_{\mathrm{FACT}}$} & \multicolumn{2}{|c|}{$\mathrm{DEE}_{\mathrm{HR}}$} & \multicolumn{2}{|c|}{ MEI } \\
\hline & Mean & SD & Mean & SD & Mean & SD & Mean & SD & Mean & SD \\
\hline $\begin{array}{l}\text { Men } \\
\text { total } \\
\text { Women }\end{array}$ & $11.0+\ddagger$ & $1 \cdot 1$ & $12 \cdot 8$ & $3 \cdot 1$ & $12 \cdot 7$ & $2 \cdot 2$ & $13 \cdot 5$ & $2 \cdot 7$ & $10 \cdot 7 \dagger$ & $1 \cdot 3$ \\
\hline total & $8 \cdot 8 *+$ & 1.0 & 9.6 & 0.8 & 8.8 & $1 \cdot 2$ & $10 \cdot 2 \dagger$ & $1 \cdot 5$ & $7.6 *+$ & $1 \cdot 2$ \\
\hline
\end{tabular}

Mean values were significantly different from: * $\operatorname{DEE}_{\mathrm{DLW}}(P<0.02), \dagger \mathrm{DEE}_{\mathrm{FACT}}(P<0.02) ; \ddagger \mathrm{DEE} / \mathrm{HR}(P<0.02)$, using the Bland \& Altman (1986) method. 
Table 3. Sleeping metabolic rate (SMR) and mean energy costs of various activities expressed as multiples of SMR for elderly men and women

(Mean values and standard deviations)

\begin{tabular}{|c|c|c|c|c|c|c|}
\hline & \multicolumn{3}{|c|}{ Men } & \multicolumn{3}{|c|}{ Women } \\
\hline & Mean & SD & $n$ & Mean & SD & $n$ \\
\hline $\operatorname{SMR}(\mathbf{k J} / \mathrm{h})$ & 281 & 31 & 6 & 217 & 18 & 6 \\
\hline Sitting quietly & 1.26 & 0.05 & 6 & $1 \cdot 30$ & 0.08 & 6 \\
\hline Reading-writing & 1.39 & 0.05 & 6 & 1.49 & 0.14 & 6 \\
\hline Watching television & 1.43 & 0.14 & 6 & 1.61 & 0.20 & 6 \\
\hline Sitting with arm activity & 1.77 & 0.21 & 3 & 1.65 & 0.21 & 4 \\
\hline Standing with light activity & 2.05 & & 2 & $2 \cdot 34$ & $0 \cdot 18$ & 6 \\
\hline House-keeping activities & $2 \cdot 55$ & $0 \cdot 16$ & 6 & 2.78 & 0.28 & 6 \\
\hline Standing with moderate activity & 2.92 & 0.51 & 7 & & & \\
\hline Vacuum cleaner & & & & $3 \cdot 18$ & & 2 \\
\hline Gymnastics & $3 \cdot 58$ & & 2 & 3.00 & & 1 \\
\hline Yoga & 2.62 & & 1 & 2.20 & & 1 \\
\hline \multirow[t]{2}{*}{ Gardening } & $3 \cdot 33$ & 0.21 & 3 & 3.05 & 0.23 & 3 \\
\hline & up to $6^{*}$ & & 1 & & & \\
\hline Shopping & 3.28 & 0.68 & 5 & $3 \cdot 18$ & 0.54 & 5 \\
\hline Walking & 4.06 & 0.52 & 6 & 3.61 & 0.39 & 6 \\
\hline \multirow[t]{2}{*}{ Cycling } & $8 \cdot 0$ & $70 \mathrm{~W} \dagger$ & 1 & & & \\
\hline & $9 \cdot 36$ & $130 \mathrm{~W}^{\dagger}$ & 1 & & & \\
\hline Running $(11 \mathrm{~km} / \mathrm{h})$ & $11 \cdot 6$ & & 1 & & & \\
\hline
\end{tabular}

* After correction for the activity intensity using heart rate recordings.

$\dagger \mathrm{W}$, instantaneous power developed.

\section{Calorimetric chambers}

SMR and energy costs of the various activities measured in the calorimeters are presented in Table 3. Average within-subject CV of SMR measured during three nights was 2.8 (SD $1.3) \%(1.2-4.6 \%)$. Mean SMR was $29 \%$ higher in men than in women $(P<0.005)$ and ranged from 258 to $367 \mathrm{~kJ} / \mathrm{h}$ for men, and from 184 to $235 \mathrm{~kJ} / \mathrm{h}$ for women. Average withinsubject $\mathrm{CV}$ of energy expended for light to moderate-intensity activity and measured over the $3 \mathrm{~d}$ stay in the calorimeters, ranged from 4.7 to $8.5 \%$ (mean, $7.6 \%$ ). It was $6.3 \%$ for walking.

Mean energy cost varied from 1.2 to 1.8 times the SMR for light-intensity seated activities. It varied from 2.5 to 3.2 times the SMR for moderate-intensity standing activities, and increased up to 8-12 times the SMR during cycling and running.

Results for DEE $\mathrm{CAL}_{\mathrm{C}}$ are presented in Table 2. Mean $\mathrm{DEE}_{\mathrm{CAL}}$ was $25 \%$ higher in men than in women $(P<0.01)$. It ranged from 9.4 to $12.7 \mathrm{MJ} / \mathrm{d}$ for men and from 7.0 to 9.7 $\mathrm{MJ} / \mathrm{d}$ for women. For ten volunteers who kept their own activity program similar during the $3 \mathrm{~d}$ stay in the calorimeters, the within-subject $\mathrm{CV}$ of $\mathrm{DEE}_{\mathrm{CAL}}$ averaged 2.0 (SD 1.5)\% $(0 \cdot 9-5 \cdot 2 \%)$.

\section{Factorial method}

Mean difference between predicted and measured DEE during the adaptation period to the calorimeters was +0.8 (SD 2.3$) \%(-2.3$ to $+3.5 \%)$.

In free-living conditions for men, the percentage of time spent sleeping, resting, working while seated, working while standing, walking and doing sport were 36 (SD 2), 

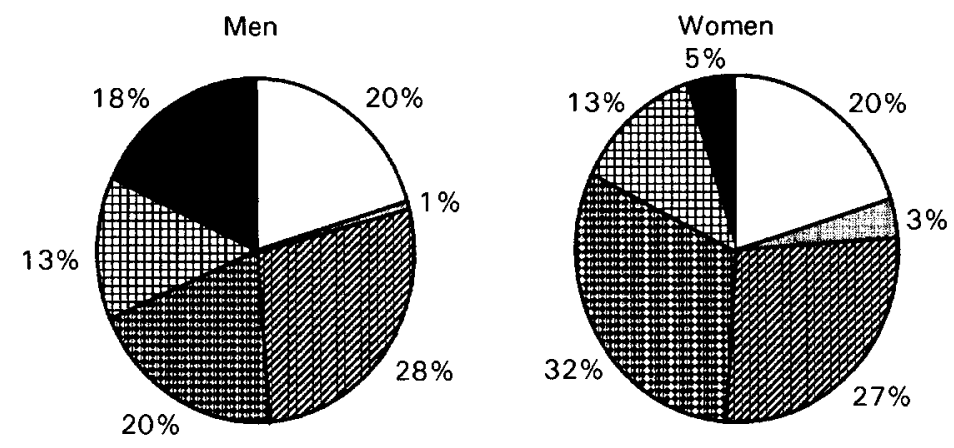

Fig. 2. Energy expended during the main types of activity expressed as a percentage of daily energy expenditure of free-

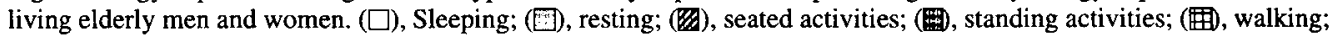
(ם), recreational activities.

1 (SD 2), 37 (SD 6), 12 (SD 6), 6 (SD 3) and 8 (SD 8) \% respectively. Similarly, for women, they were 36 (SD 6), 5 (SD 4), 31 (SD 8), 20 (SD 10), 5 (SD 3) and 3 (SD 5) \%, respectively. The corresponding EE values are presented in Fig. 2.

Mean free-living $\mathrm{DEE}_{\mathrm{FACT}}$ was $44.3 \%$ higher in men than in women $(P<0.01$; Table 2). It ranged from 10.9 to $12.8 \mathrm{MJ} / \mathrm{d}$ for five men, and reached $16.9 \mathrm{MJ} / \mathrm{d}$ for the heaviest man who practised gardening all day long. DEE $E_{\mathrm{FACT}}$ ranged from 7.4 to $10.0 \mathrm{MJ} / \mathrm{d}$ for women. Within-subject $\mathrm{CV}$ of $\mathrm{DEE}_{\mathrm{FACT}}$ calculated over $14 \mathrm{~d}$ was 12.4 (SD 5.8 ) \% $(8 \cdot 1-20.5 \%)$ for men and $6 \cdot 3$ (SD 2.2) \% (3.6-9.6\%) for women.

When using SMR measured for each subject and mean energy costs of activities from Table 3, free-living DEE was not significantly different from $\mathrm{DEE}_{\mathrm{FACT}}$, determined using individual energy costs of activities. Discrepancies between the two results averaged $-0.6(\mathrm{SD} 4.8) \%(-5.8$ to $+7.4 \%)$ for men and $0.5(\mathrm{SD} 2.8) \%(-3.3$ to $+4.5 \%)$ for women.

\section{Heart rate recording method}

Mean difference between predicted and measured $\mathrm{DEE}_{\mathrm{HR}}$ during the adaptation period to the calorimeters was -0.1 (SD 5.8) \% $(-8.3$ to $+7.6 \%)$. Results for free-living $\mathrm{DEE}_{\mathrm{HR}}$ are presented in Table 2. Mean $\mathrm{DEE}_{\mathrm{HR}}$ was $29 \%$ higher in men than in women $(P<0.01)$. It ranged from 10.8 to $18.1 \mathrm{MJ} / \mathrm{d}$ for men and from 8.0 to $11.8 \mathrm{MJ} / \mathrm{d}$ for women. Withinsubject $\mathrm{CV}$ of $\mathrm{DEE}_{\mathrm{HR}}$ calculated over $4 \mathrm{~d}$ was 11.6 (SD 7.6) \% (4.6-24.6\%) for men and $7.6(\operatorname{SD} 4.2) \%(3.9-13.6 \%)$ for women.

\section{Dietary energy intake}

No significant differences were found between ME intakes reported from the two dietary records. Mean daily $\mathrm{ME}$ intake, during the second $7 \mathrm{~d}$ dietary record, was $41 \%$ higher in men than in women $(P<0.01$; Table 2$)$. It ranged from 9.1 to $12.7 \mathrm{MJ} / \mathrm{d}$ for men and from 5.4 to $8.7 \mathrm{MJ} / \mathrm{d}$ for women. Moreover, within-subject $\mathrm{CV}$ of $\mathrm{ME}$ intake calculated over $7 \mathrm{~d}$ was $13.4(\mathrm{SD} 3.1) \%(8.5-17.4 \%$ ) for men and 16.3 (SD 8.1) \% (4.5-28.5\%) for women. 


\section{Comparisons of methods}

Comparisons of methods using the Bland \& Altman (1986) method are presented in Table 2. Discrepancies between $\mathrm{DEE}_{\mathrm{FACT}}$ or $\mathrm{DEE}_{\mathrm{HR}}$ and $\mathrm{DEE}_{\mathrm{DLW}}$ were not significant and were independent of the level of free-living DEE for both sexes (Fig. 3). Differences between $\mathrm{DEE}_{\mathrm{FACT}}$ and $\mathrm{DEE}_{\mathrm{DLW}}$ averaged -0.9 (SD 11.8)\% $(-13.9$ to $+17.7 \%)$ in men and -7.7 (SD 12.7)\% $(-21.9$ to $+12.3 \%)$ in women. Differences between $\mathrm{DEE}_{\mathrm{HR}}$ and DEE $_{\text {DLW }}$ were +4.5 (SD 14.4) \% ( -9.0 to $\left.+32.3 \%\right)$ in men and +5.9 (SD 8.8) \% $(-4.5$ to $+16.2 \%)$ in women. $\mathrm{DEE}_{\mathrm{HR}}$ was on average 10.9 (SD 12.4) \% (-15.4 to $\left.+25.1 \%\right)$ higher than DEE $E_{\mathrm{FACT}}$ calculated over the same period of time (4d) (NS). The difference increased to $+33.0 \%$ for one subject who had light-to-moderate housekeeping activities.
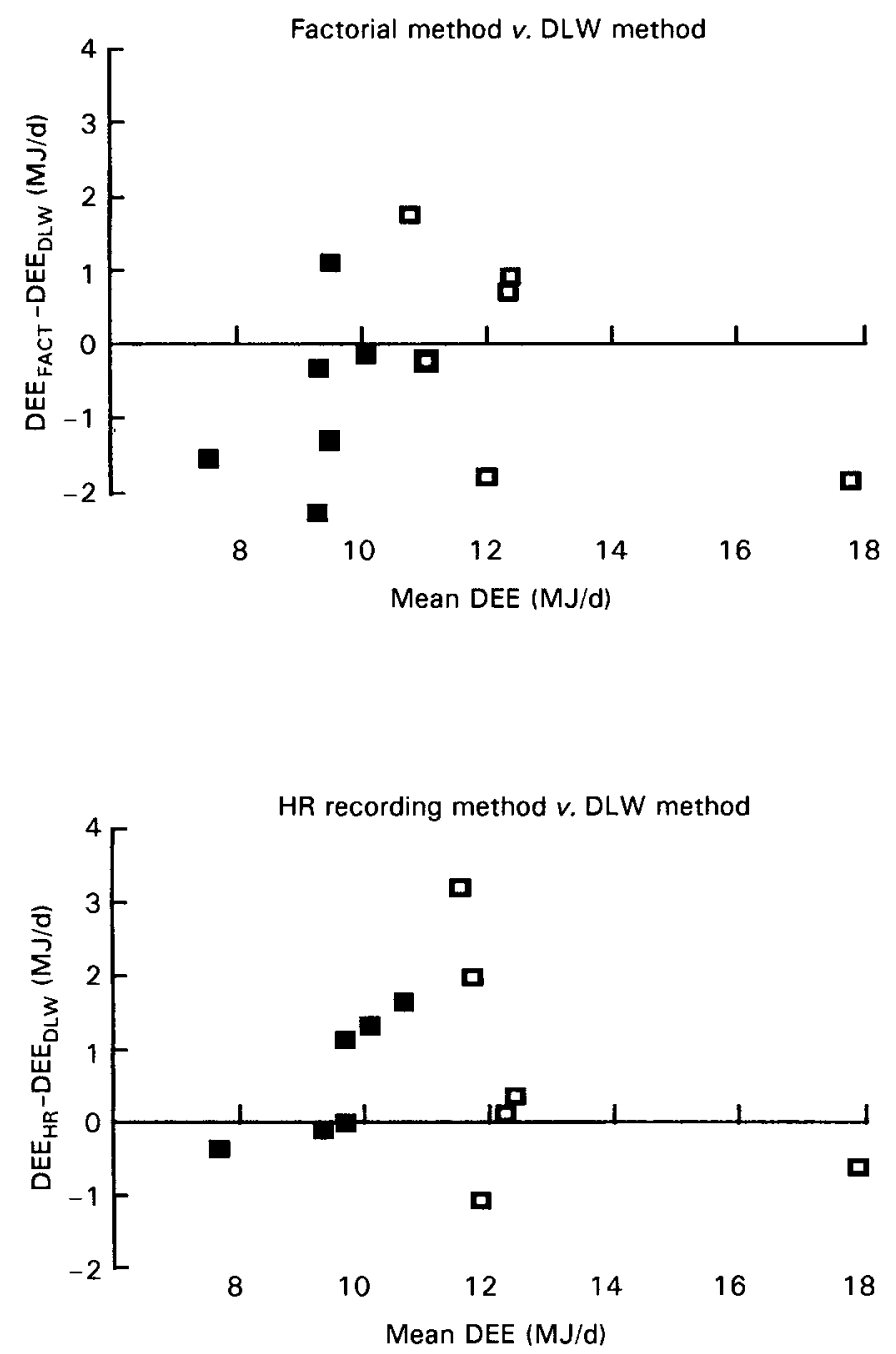

Fig. 3. Differences between daily energy expenditure (DEE) of elderly subjects determined using the factorial (FACT) or the heart rate (HR) recording method and the doubly-labelled water (DLW) method, expressed as a function of the mean DEE between the factorial or HR recording methods and the DLW method as described in the Bland \& Altman (1986) method. (ם), Women; ( $\square$ ), men. 
Discrepancies between ME intakes calculated from the second dietary intake record and $\mathrm{DEE}_{\mathrm{DLw}}$ were significant in women but not in men, when using the Bland \& Altman (1986) method (Table 2). ME intake was 13.0 (SD 20.2) \% (-41.1 to $+11.3 \%$ ) and 20.3 (SD 12.8$) \%(-42.7$ to $-3.1 \%)$ lower than $\mathrm{DEE}_{\mathrm{DLW}}$ in men and women respectively.

\section{DISCUSSION}

Measurement of respiratory gas exchanges in room calorimeters is the reference method for EE determination, whereas the DLW method has been developed for the measurement of DEE in free-living conditions (Schoeller, 1988). Since the DLW method is non-invasive and non-restrictive, it has been used in various situations, from sedentary to very active subjects, over periods of time from 5 to $10 \mathrm{~d}$ in children and 10 to $20 \mathrm{~d}$ in adults (Black et al. 1996). Validation of the method, by simultaneous measurement of DEE in calorimeters, showed that accuracy of the DLW method in groups of adults ranged from 0.6 to $2.5 \%$ (reviewed in Ritz \& Coward, 1995). However, CV of the differences, which ranged from 1.3 to $7.0 \%$ in these studies, showed inter-individual discrepancies between the two methods. The analytical precision of the DLW method was calculated to be $4.5 \%$ (Schoeller \& Hnilicka, 1996) but was found to be variable between laboratories (Schoeller \& Hnilicka, 1996). It can be improved by several means that were taken into account in the present study: high dose of deuterium to increase the accuracy of the determination of ${ }^{2} \mathrm{H}$ disappearance rate (Ritz \& Coward, 1995), observation period of $17 \mathrm{~d}$ (two biological ${ }^{2} \mathrm{H}$ half-lives, which averaged $8 \mathrm{~d}$ ) (Schoeller, 1988), multipoint analysis for the calculation of the isotope disappearance rates (Cole \& Coward, 1992) and correction for the isotope basal abundances averaged over $8 \mathrm{~d}$ (Ritz et al. 1996), and individual mean RQ measured in the calorimeters. In the present study, imprecision arising from analytical error was $1.9 \%$. Using the model derived from Ritz et al. (1996), the contribution of isotope basal abundance variations to imprecision in $\mathrm{CO}_{2}$ production calculation would amount to $3.2 \%$ in elderly people. This error was factored out by averaging isotope basal abundances over $8 \mathrm{~d}$.

In the present study the DLW method could not be validated against whole-body indirect calorimetry since the volunteers spent only $3 \mathrm{~d}$ in the calorimeters. $\mathrm{DEE}_{\mathrm{CAL}}$ underestimated energy requirements in free-living conditions as suggested by Seale (1995) and Visser et al. (1995a), despite an activity program adapted to each volunteer's habits and tested during $1 \mathrm{~d}$ before the measurement period. This probably resulted from reduced spontaneous activities, such as walking around, or from a lower intensity of some simulated activities, such as gardening, in the calorimeters.

The factorial and the HR recording methods are alternative methods for determining DEE of elderly people in free-living conditions. However, the two methods had to be calibrated by whole-body indirect calorimetry and validated against the DLW method and the advantages and limits of each method had to be evaluated. The factorial method was calibrated with measurements performed during the $3 \mathrm{~d}$ stay in the calorimeters. This permitted accurate measurement of SMR and energy expended during the various usual activities for each volunteer. The precision of the factorial method relies on (1) the SMR measurement, (2) the determination of the energy cost of the various activities and (3) the activity recordings.

Validation of the factorial method showed good agreement between DEE $\mathrm{FACT}_{\text {and }}$ $\mathrm{DEE}_{\mathrm{CAL}}$ during the adaptation period to the calorimeters. Therefore, the factorial method gave satisfactory estimates of individual DEE. Differences ranged from -2.3 to $+3.5 \%$ in the present study whereas greater differences were found in young adults $(-17$ to 
$+25 \%$, Geissler et al. 1986). However, the authors used a predicted BMR for sleeping EE and a limited number of activities measured outside the calorimeters using a mouthpiece, which could bias the intensity of some activities. Therefore, direct measurements of SMR and $E E$ of the various activities are required to improve the accuracy of the factorial method. Furthermore, if the energy costs of the various activities are related to BMR or SMR, precise measurement of the reference value is required, since a $10 \%$ misdetermination of BMR or SMR results in a $10 \%$ misdetermination of DEE. In the present study, SMR was chosen as the reference value for the factorial method since it was determined over $6 \mathrm{~h}$ and its within-subject $\mathrm{CV}(2 \cdot 8 \%)$ was lower than that of BMR (4.6$7.8 \%$ ) obtained by several authors in elderly people (Calloway \& Zanni, 1980; Pannemans \& Westerterp, 1995; Visser et al. 1995b).

Energy costs of activities obtained in the present study are within the range of those previously reported (Calloway \& Zanni, 1980; Food and Agriculture Organization/World Health Organization/United Nations University, 1985; Voorrips et al. 1993; Visser et al. $1995 c$ ). However, data are not directly comparable since the present results are expressed as multiples of SMR and the others as multiples of BMR. The error propagation arising from measurements of energy cost of activities is smaller than that of SMR. For example, a $10 \%$ error in the energy cost of standing activities (Table 3) would result in an approximately $3 \%$ error in the determination of DEE of elderly women. Consequences for DEE estimation of inter-individual variation of energy costs of activities were analysed in the present study. The results showed that the mean energy costs of activities provided in Table 3 can be used for determining free-living DEE of elderly people. However, care has to be taken for the determination of energy costs of high-intensity activities.

In free-living conditions, no significant differences were found between DEE $_{\mathrm{DLW}}$ and $\mathrm{DEE}_{\mathrm{FACT}}$ but inter-individual discrepancies showed that the factorial method is more suitable for free-living DEE of groups of subjects than of individuals. Furthermore, Visser et al. (1995c) suggested that activities could be under-recorded by elderly subjects, especially periods of time spent walking around (Visser et al. 1995a).

The percentages of time spent lying and sitting, standing with various activities or walking were similar for men and women, but men tended to perform higher intensity standing activities than women. The present results agree with those of Visser et al. (1995a) who showed that elderly women spent $73 \%$ of time lying or seated, $20 \%$ standing with light-to-moderate intensity activities and $7 \%$ walking, cycling or performing recreational activities.

The accuracy of the HR recording method mainly relies on the individual HR-EE relationship calibration. In the present study the accuracy of the HR-EE relationship was increased by pooling the $3 \mathrm{~d}$ recordings in the calorimeters to take into account the day-today variation in HR-EE relationship (Christensen et al. 1983), and computing data over 30 min periods which reduced bias due to artefactual values.

When validating the HR recording method against whole-body indirect calorimetry, the range of differences between predicted and measured DEE was larger $(-8.3$ to $+7.6 \%)$ than the factorial method $(-2.3$ to $+3.5 \%)$. Therefore, determination of individual DEE is less accurate using the HR recording method than using the factorial method. Larger ranges of differences $( \pm 10$ to $\pm 20 \%)$ were found by other authors in children (Emons et al. 1992) and adults (Spurr et al. 1988; Ceesay et al. 1989). The differences were probably a result of calibrations over short periods of time using a face mask or mouthpiece which could cause distress and discomfort, and therefore influence the HR-EE relationship as discussed by Acheson et al. (1980), and lack of measurement during sleep. 
In free-living conditions, discrepancies between $D_{D E} E_{D L W}$ and $D_{E E} E_{H R}$ were not significant and were independent of the level of DEE. This means that the HR recording method can be used in sedentary to very active subjects when the HR-EE relationship is accurately calibrated for each subject, provided the prediction equations fit for sleep and high intensity activities. The present result does not agree with that of Christensen et al. (1983), who suggested that the method was not suitable for the determination of DEE of subjects with low physical activity level. Inter-individual discrepancies between $\mathrm{DEE}_{\mathrm{DLW}}$ and DEE $E_{\mathrm{HR}}$ were similar to those obtained by Livingstone et al. $(1990)(-17$ to $+19 \%)$, and showed that the HR recording method is more suitable for the determination of freeliving DEE of groups of subjects than of individuals.

$\mathrm{DEE}_{\mathrm{HR}}$ was on average $13 \%$ higher than $\mathrm{DEE}_{\mathrm{FACT}}$ over the same days (NS). Similar differences were found by Spurr et al. (1996), when comparing the two methods in healthy Colombian women: $+13 \%$ for moderate physical activity levels and $+21 \%$ for high physical activity levels. These discrepancies could partially result from (1) the limit of accuracy of the HR-EE relationships, (2) under-recording of activities and/or (3) underestimation of the energy costs of high-intensity activities which were measured in a restricted environment. The accuracy of DEE estimation could be improved by using the two methods simultaneously. In fact, the energy cost of particular physical activities such as gardening could be corrected by using HR recordings. Conversely, the energy costs of light-to-moderate-intensity activities could be used to correct deviant results, since the HR-EE relationship is not strong during these activities.

Furthermore, the factorial and the HR recording methods also provide information about the nature or intensity of activities and about day-to-day variations in free-living DEE. The within-subject CV of DEE was similar for the factorial and the HR recording methods. It averaged $12 \%$ for men and $7 \%$ for women.

Finally, the present results confirm the discrepancies between free-living DEE $\left(\mathrm{DEE}_{\mathrm{DLW}}\right)$ and reported $\mathrm{ME}$ intakes (Black, 1996). In the present study, the underrecording of food intakes even after detailed advice from a dietitian was particularly marked in elderly women ( $-20 \%$ on average). This is in agreement with data obtained in elderly subjects (Goran \& Poehlman, 1992; Pannemans \& Westerterp, 1993; Visser et al. $1995 a$ ), where mean differences between DEE and ME intakes ranged from 10-12\% up to $31 \%$. Therefore, dietary records inform about nutritional habits but underestimate energy requirements.

In conclusion, the cost of the equipment needed for the three methods available for the determination of free-living DEE (DLW, factorial and HR recording methods) could limit their use. The DLW method is a reference method for the determination, over several days, of mean free-living DEE in groups of subjects. The factorial and the HR recording methods are satisfactory alternatives to the DLW method when considering the mean DEE of a group. Therefore, the two methods are suitable for epidemiological studies. They give information about day-to-day variations of DEE of sedentary to very active elderly subjects and could be complementary. The factorial method is dependent on the subject's cooperation for the activity reportings but gives satisfactory estimates of individual DEE. Furthermore, mean energy costs of activities as measured in the present study could be used when individual energy costs of activities are missing, provided that the reference value (i.e. SMR or BMR if SMR measurement is not feasible) is carefully and accurately measured, whereas the HR recording method relies inevitably on whole-body indirect calorimetry measurements to calibrate the individual HR-EE relationships. 
The present study was supported by Ministère de l'Enseignement Supérieur et de la Recherche Grant 92 G 0478. The authors are grateful to Dr Alain Chamoux for his cooperation and his technical assistance in making possible the heart-rate recordings and their exploitation using the LAC 943 software (Dr A. Chamoux, Faculté de Médecine, Clermont Ferrand, France). The authors thank also Yves Boirie, Pierre Gachon, Christophe Montaurier, Paulette Rousset and Guy Manlhiot for their cooperation and their skilled assistance, Dr Richard Taylor for revising the English, and the volunteers for their participation in the study.

\section{REFERENCES}

Acheson, K. J., Campbell, I. T., Edholm, O. G., Miller, D. S. \& Stock, M. J. (1980). The measurement of daily energy expenditure: an evaluation of some techniques. American Journal of Clinical Nutrition 33, 1155-1164.

Bitar, A., Vermorel, M., Fellmann, N., Bedu, M., Chamoux, A. \& Coudert, J. (1996). Heart-rate recording method validated by whole-body indirect calorimetry in 10-year-old children. Journal of Applied Physiology 81, 1169-1173.

Black, A. E. (1996). Physical activity levels from a meta-analysis of doubly labeled water studies for validating energy intake as measured by dietary assessment. Nutrition Reviews 54, 170-174.

Black, A. E., Coward, W. A., Cole, T. J. \& Prentice, A. M. (1996). Human energy expenditure in affluent societies: an analysis of 574 doubly-labelled water measurements. European Journal of Clinical Nutrition $\mathbf{5 0 ,}$ 72-92.

Bland, J. M. \& Altman, D. G. (1986). Statistical methods for assessing agreement between two methods of clinical measurement. Lancet 1, 307-310.

Calloway, D. H. \& Zanni, E. (1980). Energy requirements and energy expenditure of elderly men. American Journal of Clinical Nutrition 33, 2088-2092.

Ceesay, S. M., Prentice, A. M., Day, K. C., Murgatroyd, P. R., Goldberg, G. R. \& Scott, W. (1989). The use of heart rate monitoring in the estimation of energy expenditure: a validation study using indirect whole-body calorimetry. British Journal of Nutrition 61, 175-186.

Christensen, C. C., Frey, H. M. M., Foenstelien, E., Aadland, E. \& Refsum, H. E. (1983). A critical evaluation of energy expenditure estimates based on individual $\mathrm{O}_{2}$ consumption/heart rate curves and average daily heart rate. American Journal of Clinical Nutrition 37, 468-472.

Cole, T. J. \& Coward, W. A. (1992). Precision and accuracy of doubly labeled water energy expenditure by multipoint and two-point methods. American Journal of Physiology 263, E965-E973.

Dalosso, H. M., Morgan, K., Bassey, E. J., Jebrahim, S. B., Fentem, P. H. \& Avie, T. H. D. (1988). Levels of customary physical activity among the old and the very old living at home. Journal of Epidemiology and Community Health 42, 121-127.

Elia, M. (1991). Energy equivalents of $\mathrm{CO}_{2}$ and their importance in assessing energy expenditure when using tracer techniques. American Journal of Physiology 260, E75-E88.

Emons, H. J. G., Groenenboom, D. C., Westerterp, K. R. \& Saris, W. H. M. (1992). Comparison of heart rate monitoring combined with indirect calorimetry and the doubly labelled water $\left({ }^{2} \mathrm{H}^{18} \mathrm{O}\right)$ method for the measurement of energy expenditure in children. European Journal of Applied Physiology 65, 99-103.

Food and Agricultural Organization/World Health Organization/United Nations University (1985). Energy and Protein Requirements. Technical Report Series no. 724. Geneva: WHO.

Forbes, G. B. \& Reina, J. C. (1976). Adult lean body mass declines with age: some longitudinal observations. Metabolism 19, 653-663.

Geissler, C. A., Dzumbira, T. M. \& Noor, M. I. (1986). Validation of a field technique for the measurement of energy expenditure: factorial method versus continuous respirometry. American Journal of Clinical Nutrition 44, 596-602.

Gonfiantini, R. (1978). Standards for stable isotope measurements in natural compounds. Nature 271, $534-536$.

Goran, M. I. \& Poehlman, E. T. (1992). Total energy expenditure and energy requirements in healthy elderly persons. American Journal of Physiology 263, E950-E957.

Livingstone, B. E., Coward, W. A., Prentice, A. M., Davies, P. S. W., Strain, J. J., McKenna, P. G., Mahoney, C. A., White, J. A., Steward, C. M. \& Kerr, M. J. J. (1992). Daily energy expenditure in free-living children: comparison of heart-rate monitoring with the doubly labeled water $\left({ }^{2} \mathrm{H}^{18} \mathrm{O}\right)$ method. American Journal of Clinical Nutrition 56, 343-352.

Livingstone, B. E., Prentice, A. M., Coward, W. A., Ceesay, S. M., Strain, J. J., McKenna, P. G., Nevin, G. B., Barker, M. E. \& Hickey, R. J. (1990). Simultaneous measurement of free-living energy expenditure by the doubly labeled water method and heart-rate monitoring. American Journal of Clinical Nutrition 52, 59-65. 
Pannemans, D. L. E. \& Westerterp, K. R. (1993). Estimation of energy intake to feed subjects at energy balance as verified with doubly labelled water: a study in the elderly. European Journal of Clinical Nutrition 47, 490496.

Patrick, J. M., Bassey, E. J., Irving, J. M., Blecher, A. \& Fentem, P. H. (1986). Objective measurements of customary physical activity in elderly men and women before and after retirement. Quaterly Journal of Experimental Physiology 71, 47-58.

Prentice, A. M. (1992). Energy expenditure in the elderly. European Journal of Clinical Nutrition 46, S21-S28.

Ritz, P., Cole, T. J., Couet, C. \& Coward, W. A. (1996). Precision of DLW energy expenditure measurements: contribution of natural abundance variations. American Journal of Physiology 270, E164-E169.

Ritz, P. \& Coward, W. A. (1995). Doubly labelled water measurement of total energy expenditure. Diabète et Métabolisme 21, 241-251.

Schoeller, D. A., Van Santen, E., Peterson, D. W., Dietz, W., Jaspan, J. \& Klein, P. D. (1980). Total body water measurement in humans with ${ }^{18} \mathrm{O}$ and ${ }^{2} \mathrm{H}$ labeled water. American Journal of Clinical Nutrition 33, 26862693.

Schoeller, D. A. (1988). Measurement of energy expenditure in free-living humans by using doubly labeled water. Journal of Nutrition 118, 1278-1289.

Schoeller, D. A. \& Hnilicka, J. M. (1996). Reliability of the doubly labeled water method for the measurement of total daily energy expenditure in free-living subjects. Journal of Nutrition 126, 348S-354S.

Seale, J. L. (1995). Energy expenditure measurements in relation to energy requirements. American Journal of Clinical Nutrition 62, Suppl, 1042S-1046S.

Sheng, H. P. \& Huggins, R. A. (1979). A review of body composition studies with emphasis on total body water and fat. American Journal of Clinical Nutrition 32, 630-647.

Spurr, G. B., Dufour, D. L. \& Reina, J. C. (1996). Energy expenditure of urban Colombian women: a comparison of patterns and total energy expenditure by the heart rate and factorial methods. American Journal of Clinical Nutrition 63, 870-878.

Spurr, G. B., Prentice, A. M., Murgatroyd, P. R., Goldberg, G. R., Reina, J. C. \& Christman, B. S. (1988). Energy expenditure from minute-by-minute heart-rate recording: comparison with indirect calorimetry. American Journal of Clinical Nutrition 48, 552-559.

Vermorel, M., Bitar, A. \& Vernet, J. (1995). Calorimétrie indirecte. 3 - Contrôle de la validité des mesures des échanges respiratoires des animaux et des humains (Control of the respiratory exchange measurements validity in animals and human beings). Cahiers des Techniques de l'INRA 35, 63-76.

Visser, M., de Groot, L. C. P. G. M., Deurenberg, P. \& van Staveren, W. A. (1995a). Validation of dietary history method in a group of elderly women using measurements of total energy expenditure. British Journal of Nutrition 74, 775-785.

Visser, M., Deurenberg, P., van Staveren, W. A. \& Hautvast, J. G. A. J. (1995b). Resting metabolic rate and dietinduced thermogenesis in young and elderly subjects: relationship with body composition, fat distribution, and physical activity level. American Journal of Clinical Nutrition 61, 772-778.

Visser, M., van der Horst, A., de Groot, L. C. P. G. M., Deurenberg, P. \& van Staveren, W. A. (1995c). Energy cost of physical activities in healthy elderly women. Metabolism 44, 1046-1051.

Voorrips, L. E., van Acker, T. M. C. J., Deurenberg, P. \& van Staveren, W. A. (1993). Energy expenditure at rest and during standardized activities: a comparison between elderly and middle-aged women. American Journal of Clinical Nutrition 58, 15-20.

Weir, J. B. de V. (1949). New methods for calculating metabolic rate with special reference to protein metabolism. Journal of Physiology 109, 1-9.

Wong, W. W., Lee, L. S. \& Klein, P. D. (1987). Deuterium and oxygen-18 measurements on microliter samples of urine, plasma, saliva and human milk. American Journal of Clinical Nutrition 45, 905-913. 